\title{
Formas de vivencia, convivencia y supervivencia en el sector centro de Bogotá
}

Forms of experience, coexistence and survival in the industry center of Bogotá

SANDRA LILIANA PINZÓN DAZA

Docente asociada de la Universidad Jorge Tadeo Lozano, Bogotá, Colombia. Correo electrónico: sandra.pinzon@utadeo.edu.co

\section{Resumen}

El estudio de las ciudades lleva inmerso el análisis de las prácticas sociales de los diferentes grupos humanos que allí confluyen, así como de las relaciones de los individuos con los espacios, lugares y actividades, propios de los centros urbanos. En el caso del centro urbano de la ciudad de Bogotá, comprendido en esta muestra entre las calles 19 a la 32 y las carreras tercera a la séptima, es posible describir las categorías de vivencia, convivencia y supervivencia que allí se observan, a partir de las estrategias para solucionar los problemas y las necesidades diarias de los grupos humanos que allí habitan o confluyen, y de las actividades que estructuran y diseñan la relación filial de los sujetos con su entorno. Lo anterior permite construir mapas cognitivos de los habitantes, comerciantes y transeúntes del sector centro de la ciudad de Bogotá. Para ello nos basamos en aspectos teóricos que revisan las diferencias entre las

\section{Abstract}

The study of cities has immersed the analysis of the social practices of the different human groups that converge there, as well as the relationships of individuals with spaces, places and activities, characteristic of urban centers. In the case of the urban center of Bogotá, understood in this sample among the 19 streets to the 32nd and 3rd to the seventh races, it is possible to describe the categories of experience, coexistence and survival that there are observed, from strategies to solve problems and the daily needs of human groups that live there or come together, and activities that structure and design subject's subsidiary relationship with their environment. This allows building cognitive maps of residents, merchants and passersby sector center of the city of Bogotá. To do this we rely on theoretical aspects that reviewed the differences between the notions of territory, space and place; proposed by Bourdieu (1990) 
nociones de territorio, espacio y lugar; lo propuesto por Bourdieu (1990) en torno a las nociones de campo y habitus; y acudimos a la denominación de mapas cognitivos construida por Lee (1976), Milgram (1977). Bell, Fisher, Baum y Green (1996). Lynch (1960).

Palabras clave

Vivencia - convivencia supervivencia - territorio - mapas cognitivos around the notions of field and habitus; and we went to the denomination of maps cognitive built by Lee (1976), Milgram (1977). Bell, Fisher, Baum and Green (1996). Lynch (1960).
Keywords

Cognitive maps - survival territory - coexistence

\section{Introducción}

El reconocimiento de los sectores que configuran las redes sociales, culturales y económicas de una ciudad, permite identificar y describir los rasgos y conductas de los sujetos que allí habitan, transitan o confluyen. Sus prácticas cotidianas en términos de vivienda, trabajo, tensiones y convivencia social son una manifestación de las dinámicas que los espacios y lugares les posibilitan. En el caso concreto del sector centro de la ciudad de Bogotá, tomado en este estudio entre las calles 19 a la 32, entre las carreras 3era y séptima, es posible leerlo como una muestra de los diversos tipos y modalidades de intercambio entre los diferentes grupos humanos, así como una caracterización de las nociones de lugar y de espacio dentro de la ciudad.

Habitar una ciudad es habitar unos modos de estar allí, de definirse y de entrar en un intercambio de experiencias individuales y colectivas, transitorias o permanentes. Cada espacio, cada lugar y cada actividad, se carga de sentido a través de las diferentes categorías utilizadas para percibirlas, representarlas y expresarlas con palabras, por parte de los diferentes grupos humanos que allí confluyen. Es así como la ciudad se configura a partir de pequeños o grandes fragmentos de vida que de una u otra manera permiten tejer historias. Con especial énfasis al referir a los centros urbanos, es preciso identificar la manera como convergen relatos que se alimentan con la presencia de grupos humanos de otras regiones, de otras culturas y con otros ritmos de vida. La irrupción de nuevas prácticas, la apertura de sitios nuevos para satisfacer necesidades o el establecimiento de los puestos informales en plena calle, son el reflejo de otros modos, medios y formas de vivencia, convivencia y supervivencia.

El estudio que acá se plantea quiere diseñar una cartografía social a partir de las categorías de vivencia, convivencia y supervivencia, con el propósito de documentar la manera como en este sector de Bogotá se pone en contacto el hombre con su espacio, a través de elementos tangibles, como son los rasgos y 
características particulares de los lugares y las relaciones que se derivan, expresadas en los conceptos para aludir a ese espacio vital. El reconocimiento de los conceptos referidos busca determinar los mapas cognitivos que se constituyen sobre la base de los espacios ocupados, habitados y simbolizados.

Para tal fin, el recorrido comienza por la identificación de las nociones de territorio, espacio y lugar. Sigue con la descripción de tipo de transformaciones que se suscitan en el paso del espacio vacío a la construcción simbólica de los lugares en el sector centro de Bogotá. Finalmente, plantea el análisis de los mapas cognitivos de los habitantes y pasantes del sector centro de Bogotá, derivados de las interacciones significativas entre los grupos humanos referidos y el sector centro de la ciudad, desde una lectura social, cultural y experiencial.

\section{El sector centro de Bogotá. Territorio, espacio y lugar}

La percepción que los grupos humanos tienen sobre su entorno está determinada por las condiciones de adaptación, por las experiencias y por las estrategias para cargar de sentido los espacios que habitan. En tal sentido, cabe precisar las nociones de territorio, espacio y lugar, con el propósito de describirlos a la luz del estudio que acá se recoge sobre el sector centro de la ciudad de Bogotá. Ello porque a pesar de tantos estudios de orden demográfico, histórico, sociológico o antropológico, no se tiene un abordaje en torno a las características cognitivas y simbólicas que se derivan de la relación entre los individuos y el contexto en esta zona de Bogotá, recogidas en la descripción de los mapas mentales de los habitantes y transeúntes.

Para tratar de proponer una reflexión en esta línea, es necesario identificar inicialmente la noción de territorio. Podemos referirnos a que no es un objeto, ni es una cosa, comprende un conjunto de relaciones complejas entre los sujetos, sus prácticas y la manera en que realizan una apropiación colectiva, desde lo económico, social, afectivo, familiar y profesional. Es así como la mirada transversal que puede realizarse de esta complejidad en relación a las formas de habitar y al beneficio que reciben, es el ámbito de acción del análisis de los alcances, límites y posibilidades de la noción misma de territorio. De manera que el territorio, en este tipo de estudio, se categoriza prototípicamente como un área definida en términos institucionales normativos que determinan su identificación y su funcionamiento.

Al referir a la noción de territorio, podemos aludir a las maneras de organización de la realidad en términos económicos de supervivencia. Tal es el caso de las denominaciones de trabajo informal y vendedores ambulantes, las cuales ya determinan una designación territorial en función de las complejas relaciones que se establecen. En cuanto a la primera categoría, ésta hace parte de las consideraciones semánticas de reconocimiento de un oficio para sobrevivir, de unos medios de subsistencia que implican una apropiación de normas alternativas a las impuestas. Esto quiere decir que, en el territorio colombiano, y dentro de las disposiciones estatales y distritales de empleo, ya se reconoce esta modalidad y se caracteriza a quienes la practican, como agentes diferenciados dentro de los intercambios de producción y consumo. 
En el caso de los vendedores ambulantes, bajo esta categoría se recogen individuos o grupos procedentes de otras regiones del país, quienes vienen a probar suerte y a buscar medios de manutención para sus familias. Sin embargo, también están quienes por edad o por condiciones físicas, no pueden entrar en el universo formal de la economía y buscan medios alternativos. Es así como al referir a las condiciones particulares en que la noción de territorio se refleja en el sector centro de Bogotá, es posible determinar una confluencia de relatos de vida, bajo la categoría de supervivencia en función de los modos de producción que se fijan en una urbe capital, con el propósito de alcanzar un nivel de vida que les permita suplir las necesidades mínimas. De manera que el territorio, en el caso del centro de Bogotá, es un lugar concreto con límites y características que lo hacen potencialmente apto para crear estrategias de superación de las necesidades familiares, y adecuado para conseguir productos y servicios.

En cuanto a la noción de espacio, esta hace referencia a una conceptualización humanizada, en función de que su construcción depende directa o indirectamente de la sociedad. Podemos referir a la descripción de los centros urbanos, tomando como espacio concreto la delimitación de calles y carreras que son objeto de uso, consumo y tránsito. Para este estudio, el considerar el espacio comprendido entre las calles 19 a la 32, y las carreras 3era a séptima, obliga a la determinación de una serie de prácticas sociales, que se alimentan para su percepción y carga significativa de lo que en términos de Bourdieu (1990) será la relación dialéctica entre campo y habitus, es decir entre las estructuras sociales externas y las estructuras sociales incorporadas respectivamente por los agentes sociales a lo largo de su historia.

Lo anterior permite revisar la manera como se organiza en la mente de los sujetos, cómo se conceptualiza y a qué tipo de categorías se remite el centro de Bogotá, en las coordenadas referidas. Se trata entonces de recoger la manera como se da lectura por parte de los diferentes grupos humanos que allí confluyen, al espacio urbano en esta zona.

Si seguimos lo planteado por Bourdieu, y lo trasladamos a lo evidenciado en el estudio, al hablar de campo, debemos tomar en consideración la posición y las relaciones de posiciones de esos agentes en el espacio habitado o transitado. Es por ello por lo que se debe aludir al tipo de establecimientos que tienen su sede allí, con el propósito de comprender las posiciones que ocupan en el lugar, y quiénes son los agentes que allí establecen las relaciones.

En primer lugar es preciso referir a que en esta zona se encuentran establecimientos educativos, empresariales, gubernamentales, artísticos, comerciales, de diferentes segmentos económicos, así como edificios y casas cuyos habitantes residen hace mucho tiempo, o que hacen parte de la nueva oferta de vivienda para suplir las necesidades de quienes trabajan en esta zona, con lo cual, los agentes tendrán rasgos como estudiantes, empresarios, oficinistas, funcionarios oficiales, comerciantes, transeúntes y usuarios. De allí que la otra noción referida, la de habitus, entendida como la tendencia a pensar, sentir, percibir, valorar de los agentes, supone un estado de las relaciones de fuerzas desde las prácticas que allí se producen en función de los intereses, posibilidades, mecanismos y formas de vivencia, convivencia y supervivencia. 
De suerte que las tensiones que se reflejan en este sector pasan por la carga simbólica que tiene para quienes habitan, y conservan la añoranza de los tiempos pasados frente a la manera en que estaba dispuesto el espacio vital para disfrutar y contemplar. Por su parte tendrá la categorización para quienes frecuentan por necesidad de trabajo o estudio estos espacios, se basa en una percepción de inseguridad, la cual conlleva a la valoración negativa por la pérdida del espacio público, a manos de la economía informal, el estado lamentable de las calles con sus fétidos olores y la presencia indiscriminada de habitantes de calle, que se mezclan con la venta de productos en el espacio público. Es tal vez esta misma denominación de espacio público, la que condiciona la disposición, el funcionamiento y el control de esta parte del territorio distrital, en el cual convergen grupos humanos con diferentes necesidades y posibilidades.

Es en esta medida que la noción de campo, identificado en esta delimitación del sector centro de Bogotá, tiene las características de un espacio habitado y transitado en el cual se establecen posiciones fijas y posiciones móviles. En el primer caso están los habitantes naturales de este sector, que aún viven, quienes perciben desde el lugar de la memoria, las experiencias de antaño que marcaron su establecimiento y su permanencia en un espacio habitado, categorizado y simbolizado como neurálgico dentro del desarrollo propio de las ciudades, así como para describir los procesos de movilización de las zonas rurales a las urbanas. Adicionalmente las calles y carreras tomadas en este abordaje conservan la percepción espacial de ser un punto intermedio entre lo que los habitantes pasados denominaban el centro y las recientes dinámicas sociales, económicas y culturales que tienen lugar hacia la calle 32.

De manera que el habitus, en el caso concreto de la muestra delimitada, se caracteriza por las diversas valoraciones que se tiene de los espacios habitados y de confluencia, a partir de los diferentes roles de los agentes. Es decir, los vendedores ambulantes le cargan de un sentido económico como su espacio de supervivencia, haciendo que sea para ellos a la vez un espacio vital de luchas y confrontaciones con las normas del espacio público y con sus colegas de oficio. Por su parte, los empresarios, funcionarios, empleados y estudiantes determinan este espacio como un entorno de convivencia, en el cual confluyen establecimientos de intercambio económico, simbólico, de oferta de bienes y consumo, de diversión y por supuesto de formación académica 0 de fortalecimiento intelectual como bibliotecas y museos.

De manera que la noción de espacio en los centros, urbanos se determina y caracteriza por los modos de apropiación, adaptación e intercambio entre individuos y grupos humanos. Esta confluencia ha dado lugar a la apertura de comercio enfocado específicamente a estos transeúntes que se trasladan diariamente a este espacio, y en el cual se consolidan como elementos determinantes para el potencial económico de quienes explotan de manera formal o informal, este espacio vital.

El tercer aspecto a considerar es la noción de lugar. Para ello es importante identificar que existen lugares habitados, simbolizados, delimitados, designados, controlados y asociados con experiencias individuales o grupales. Para el caso de 
la muestra presentada, la noción de lugar se puede identificar en función de plazas, iglesias, centros culturales, ya que cada uno de ellos permite reconocer la naturaleza y las características del tipo de interacción que posibilitan y alimentan. Esto porque se establecen relaciones con el mundo, la naturaleza, con el Estado o Gobierno local y por supuesto entre sujetos, ya que se formalizan pactos, acuerdos que determinan las nociones mismas de ciudadanía y convivencia.

De ahí que la relación de los diferentes grupos humanos con los lugares, en este sector de la ciudad, está basada en los modos y medios de adaptación, apropiación y dación de sentido a través de las prácticas que allí se realizan. El caso concreto es la carga significativa que ha adquirido la peatonalización de la carrera séptima como lugar de mercado ambulante, de movilizaciones ciudadanas y de encuentro de experiencias e historias de vida que se entrecruzan, haciendo que se categorice como un lugar neurálgico de confluencia y convivencia.

A continuación, y a partir de las nociones descritas a la luz del sector tomado como muestra, planteamos las formas de relación de los grupos humanos, los espacios y los lugares, con el fin de entender en qué medida se configuran desde las operaciones cognitivas de percepción, atención y memoria, en torno a las dinámicas propias de los centros urbanos. Se trata entonces de revisar, la manera como los sujetos y grupos humanos conciben su relación con los espacios y lugares que habitan y por los cuales transitan cotidianamente.

\section{Del espacio vacío a la construcción simbólica de los lugares en el sector centro de Bogotá}

Los diferentes abordajes sobre la descripción y el análisis de las dinámicas propias de los centros urbanos, permite reconocer que la significación de las ciudades, así como sus formas de categorización, están dadas por los grupos humanos que habitan, confluyen o transitan por los diferentes espacios de un territorio, así como por el tipo de lugares que cargan de sentido a través de intercambios sociales, culturales simbólicos y económicos. En el caso específico del estudio que se quiere mostrar, es posible identificar los rasgos que definen este sector de la ciudad en términos del tipo de construcción simbólica. Es decir, en función de la manera de comprender el tipo de relación que se establece entre los individuos que habitan y configuran un determinado lugar, y las características de los diferentes espacios que permite una ciudad.

Sobre esta base, entender la relación de la sociedad con el entorno que habita, tiene que ver con la determinación de las tensiones y de dinámicas de configuración de sentido por parte de los diferentes grupos humanos que van poblando los espacios y lugares de la ciudad. De manera que el valor real de esos espacios y la condensación del simbolismo del que se cargan los lugares por parte de quienes los apropian, pasa por la asociación con las experiencias, percepciones y la condensación de memoria que tienen desde lo afectivo, lo económico o la asociación con el valor de ese lugar al interior del todo del que hace parte. Tal es el caso de la delimitación de la muestra que se ha 
Perspectivas Revista de Ciencias Sociales - ISSN 2525-1112 |Año 2 No. 4 Julio-Diciembre 2017, pp. 165-177

considerado, ya que permite recoger los rasgos determinantes de la muestra total que sería el centro en toda su extensión.

\section{Análisis de mapas cognitivos de habitantes y pasantes del sector centro de Bogotá}

Al momento de desplazarse dentro de la ciudad, los sujetos necesitan de elementos que les permitan orientarse, adaptarse y apropiarse del espacio que habitan o en el cual confluyen. En este contexto, los hitos urbanos (elementos del paisaje fácilmente visibles) juegan un papel orientador de importancia, puesto que se transforman en puntos de referencia insertos en la ciudad. Así, los diferentes grupos humanos, e individuos, quienes, por ser habitantes del sector referido, por dirigirse allí por intereses laborales o educativos, van incorporando y adoptando elementos que para ellos sean significativos, simbólicos o simplemente les permitan un intercambio en términos económicos, sociales o culturales. En tal sentido, las conductas espacio-temporales se manifiestan en el tipo de percepción y configuración de los elementos, objetos, prácticas y dinámicas que allí tienen lugar.

A partir de lo anterior, es posible establecer los procesos cognitivos que se estructuran en la mente de los sujetos y grupos humanos que habitan o transitan este lugar, a partir de las formas de apropiación y simbolización de los espacios vitales. Para ello es necesario referir a la determinación de que los individuos que hacen parte del sector centro de la ciudad de Bogotá, están inmersos en una realidad que debe ser aprendida y aprehendida. De suerte que esas diversas y contradictorias maneras de cargar de sentido un lugar, pueden interpretarse desde la identificación y análisis de dos aspectos propios de las formas de construcción del conocimiento humano como son la imagen material y la imagen mental.

Cuando se habla de imagen material, no se está haciendo más que eliminar toda carga valorativa que puede contener el espacio, ya que se trata de la objetivación máxima representada, por ejemplo, en el plano de una ciudad, en términos de disposición física y espacial recogida en límites y señales convencionalizadas por la norma. En tal sentido, referimos a la imagen material desde el plano físico que se puede percibir de un lugar, o de un territorio a través de la observación y apropiación de su configuración en función de objetos y ubicación de éstos en el plano. De manera que allí cobra relevancia su contraste con la imagen mental, ya que tal como hace referencia De Castro (1997), lo que se ha dado en llamar imagen material dista mucho de la imagen mental, porque cuando el sujeto está inmerso en el espacio, filtra todo cuanto le rodea mediante los procesos cognitivos.

De allí que cada uno de los grupos humanos que confluyen en el sector comprendido entre las calles 19 a la 32 y las carreras 3era a la séptima en el sector centro de la ciudad de Bogotá, pueden tener acceso visual y físico a los mismos objetos dispuestos en los diferentes espacios, en tanto reconocimiento de una serie de imágenes materiales. Sin embargo, al considerar los procesos cognitivos que cada uno de ellos realiza como la atención, la memoria, la percepción y la experiencia, cada uno de los objetos se cargará de potencial 
simbólico o de uso, según los intereses, necesidades y formas de captar y configurar estos objetos en tanto imágenes mentales.

Un aspecto importante por considerar es la manera como los objetos dispuestos en el espacio público, así como en los lugares que allí se establecen para suplir diferentes necesidades, adquieren un valor simbólico para los diversos grupos humanos en función de las categorías de vivencia, convivencia y supervivencia. De manera que en sí mismos los espacios, los objetos y las estructuras propias de la ciudad, y de sus diferentes sectores, no tienen un valor concreto, más allá de la configuración propia de hacer parte de un sector definido de la ciudad. Son los sujetos, a través de sus diferentes prácticas, apropiaciones y adaptaciones, quienes logran cargar de sentido los objetos, los espacios y los lugares, a partir de las valoraciones emocionales, colectivas, productivas y simbólicas que se configuran como imágenes mentales.

Es así como la manera en que se establece esa relación entre los grupos humanos, los objetos y los espacios, define la importancia que tiene el lenguaje como herramienta para determinar el potencial cognitivo de los objetos, los acontecimientos y las situaciones que intentamos armonizar con la información ya almacenada en la memoria como consecuencia de experiencias pasadas (Sternberg y otros, 1987). Dentro de este marco de reflexión que permite el estudio de la cognición humana expresada en las diferentes maneras de categorización de los espacios y las prácticas de interacción social, un proceso que permite articular las reflexiones en torno a las condiciones de vivencia, convivencia y supervivencia que se manifiestan en este sector del centro de la ciudad, tiene que ver con la atención. No cabe duda de que la atención, como proceso cognitivo, resulta ser un filtro que permite incorporar a los mapas cognitivos elementos para reconocer, abstraer y generalizar los aspectos relevantes del entorno. En tal sentido, los objetos que se perciben permiten un tipo de atención diferencial, dependiendo de los intereses, necesidades y posibilidades que cada grupo humano adjudique a determinados elementos de su contexto, así como del tipo de relación simbólica que se genere.

Tal es el caso de las calles, los andenes, el mobiliario urbano de este sector, el cual es utilizado potencialmente con diferentes cargas significativas, según se produzca un tipo de intercambio desde la mirada de un vendedor informal, de un empresario, de un empleado, de un estudiante o de un transeúnte. Esto quiere decir que la construcción de imágenes mentales, a partir de imágenes materiales, lleva condensada la capacidad perceptiva de los sujetos para interpretar y entender la información que se ha recibido a través de los sentidos. Es a partir de lo anterior que podemos hacer referencia a una posibilidad de abordaje diferente sobre el pensamiento, denominada representación. La representación estudia cómo codificamos mentalmente la información" (Hayes, 1995:37). La representación no es otra cosa que una imagen del mundo levantada en la mente del sujeto, imagen que es distinta para cada persona y en la cual intervienen diferentes variables como la edad, el género, condición socioeconómica, etc., (Banyard y otros, 1995; Sabaté y otros, 1995; GarcíaAlbea, 1986; De Castro, 1999; Sternberg y otros, 1987). Es factible afirmar que el punto determinante de los procesos cognitivos lo encontramos en la 
representación, y es precisamente este mecanismo el que funciona como nexo entre el individuo y su entorno.

Como producto de los procesos cognitivos, la representación no es un cúmulo de imágenes sin sentido. Las imágenes mentales tienen un ordenamiento coherente y son factibles de ser organizadas según la funcionalidad que representen para el ser humano (Banyard y otros, 1995; Sternberg y otros, 1987). De acuerdo con los diferentes tipos de información, las representaciones se han clasificado en:

a). Conceptos: una forma de representar una gran cantidad de información es agruparla en conceptos. Esta agrupación se realiza con el criterio de semejanza; en el concepto silla se agrupan todos los objetos percibidos que cumplan con las características que los conocimientos previos permitan distinguir como silla. "Luego, usamos esos conceptos en nuestro pensamiento, aplicándolos a nuestra comprensión de otra información” (Banyard y otros, 1995:38). La formación de conceptos es la piedra angular de otros tipos de representaciones, como son los esquemas y los guiones (Sternberg y otros, 1987).

b). Esquemas: son una forma de representación que se nutre de la formación de conceptos, pero que resulta, por definición, un proceso bastante más complejo. El esquema resulta ser un modelo hipotético de cómo se almacena la información, usándose para dirigir las relaciones entre los acontecimientos (Banyard y otros, 1985). Un esquema puede incluir toda la información referente a un suceso concreto, levantando "el conocimiento teórico y práctico sobre el acontecimiento, las ideas y opiniones sobre ello, etc." (Banyard y otros, 1995:344).

Es así como para comprender la manera en que los diferentes grupos humanos que allí confluyen configuran sus relaciones con los espacios, las prácticas y los lugares, propios de este sector, es preciso determinar los rasgos y situaciones en cada caso. De suerte que para los vendedores informales se trata de acudir a sus estructuras mentales sobre el sector centro como el espacio para la supervivencia, designado a través de rasgos de conceptualización metonímica como rebusque, algo para comer, el recurso para sacar a mi familia adelante, la competencia por sobrevivir, la lucha diaria, con lo cual este espacio ya refleja su apropiación como valor de desarrollo económico y potencial para la subsistencia. Por su parte, para los transeúntes, su conceptualización metonímica será en función de rasgos como inseguridad, desempleo, caos, desorden riesgo, contaminación, falta de reglamentación, beneficio, sacrificio. Dando lugar con ello a consideraciones particulares para este sector, las cuales se constituyen en atributos diferenciales $y$ estigmatizantes, respecto a las conductas y comportamientos individuales y colectivos, normativos y alternativos.

Es así como el paso de los espacios vacíos a los lugares simbolizados, guarda relación con las percepciones reales, imaginarias y simbólicas de quienes dentro del campo, referido por Bourdieu como las posiciones y las relaciones entre estas, adoptan un rol o una función en consideración con sus formas de vivencia, convivencia y supervivencia, frente a quienes atribuyen cargas semánticas y 
Perspectivas Revista de Ciencias Sociales - ISSN 2525-1112 |Año 2 No. 4 Julio-Diciembre 2017, pp. 165-177

conceptualizan valorativamente a los sectores urbanos como centros de confluencia de prácticas, grupos humanos y realidades, que entre más disímiles, más contribuyen a la consolidación de espacios vitales.

c). Mapas Cognitivos: en pocas palabras, el mapa cognitivo es la representación de lugares y localizaciones. Los mapas cognitivos informan la ubicación con respecto a otros lugares, además ayudan a que los desplazamientos sean eficaces. También pueden ser importantes como causa de liberación de información almacenada, proporcionando pistas útiles para nuestros recuerdos (Banyard y otros, 1995; De Castro, 1997-1999; Sternberg y otros, 1987).

A partir de lo anterior es posible hacer referencia a este espacio de la ciudad desde la relación entre las categorías concretas de ser y estar. Es decir, de ser, en tanto se ha desarrollado una apropiación simbólica de los límites, las prácticas y el lugar de los agentes dentro de las condiciones naturales del espacio. Y de estar, por la capacidad de los transeúntes y pasantes de adecuar su cotidianidad al ritmo de los lugares y grupos humanos que allí convergen. De manera que la categoría de ser está enmarcada por la memoria colectiva que tiene este espacio, y la condensación de atributos y experiencias cargadas de diversos valores que se asumen dentro de las posiciones de habitantes, comerciantes y pasantes.

Por su parte, la categoría de estar se configura como una percepción simbólica de experiencias diarias de movilidad, convivencia y consumo de bienes y servicios de quienes acuden a este espacio por razones diversas, pero con intereses similares, como son los de simbolizar los espacios y apropiar los lugares para las prácticas sociales de ciudadanía. En tal sentido, las categorías de ser y estar no son roles que se intercambian en el continuo trasegar de la existencia de los sujetos, son actitudes cargadas de valores reales, imaginarios o simbólicos sobre los espacios.

Se trata por ejemplo de una plaza o un andén vacíos, los cuales adquieren su condición de espacio vital para quien los adecúa como lugares de vivencia, mientras que para los comerciantes tendrán la carga imaginaria de supervivencia en función de un intercambio potencial de bienes o servicios. Y para quienes diariamente se trasladan por necesidad de trabajo formal o estudio a estos espacios, son reconocidos bajo el simbolismo de ser el espacio donde se concentra la memoria y la percepción histórica que refleja la noción de centro configurador de una ciudad.

Es en este sentido que hablar de espacios vitales y lugares simbolizados, es considerar también las formas de posesión, de afectación, de explotación y de sublimación para poder cargar con valores imaginados a esos espacios de la cotidianidad. De manera que al identificar las formas en que se manifiesta la cognición humana en función de la relación entre los individuos y el entorno, es necesario determinar las categorías que surgen de la experiencia vital con los lugares, y del intercambio con las prácticas de construcción de sentido. Para ello es importante recordar que las estructuras mentales de los sujetos se alimentan de las percepciones almacenadas, las cuales se activan conceptualmente a través 
de las valoraciones en función de las formas prototípicas de delimitar y dar lectura desde la norma espacial a los lugares que componen una ciudad. De suerte que el espacio captado por la imaginación no puede seguir siendo el espacio indiferente designado por una norma espacial o por un medidor de sectores en una ciudad.

El mapa cognitivo no es una fotografía o un plano, es una construcción mental sujeta a la diversidad de percepciones de los sujetos. La percepción, como ya se ha mencionado, es la síntesis de los procesos cognitivos, y es esta cognición la que, en definitiva, organiza la información espacial. Se acostumbra a explicar los mapas cognitivos en virtud de la relación del individuo y la ciudad. De esta forma, la percepción que se tenga de la ciudad es fundamental al momento de levantar representaciones.

De acuerdo con esta definición, el sujeto utiliza con frecuencia los mapas cognitivos, pues representan la relación individuo / mundo (Banyard y otros, 1995; De Castro, 1999), sobre todo en el reflejo de la vida cotidiana (De Castro, 1997). El mapa cognitivo vendría a ser un "dispositivo mental que orienta a diario nuestra navegación urbana" (De Castro, 1999), entendiendo que, en este caso, el dispositivo consiste en un cúmulo de información. Todo esto está referido a los desplazamientos inconscientes que se hacen dentro de la ciudad, donde el plano está interiorizado mentalmente.

En la actualidad, los mapas cognitivos muestran cómo dentro de la mente se crea una representación del mundo exterior, acercándose al levantamiento de una imagen que dista mucho de mostrar fielmente lo que ese espacio exterior es en realidad. El mapa cognitivo no es una fotografía o un plano, es una construcción mental sujeta a la diversidad de percepciones de los sujetos.

La experiencia de peatón puede ser considerada el primer peldaño del aprendizaje sobre el entorno (De Castro, 1997), y es también el inicio de una de las dificultades que manifiesta el ser urbano: los desplazamientos. Los desplazamientos dentro de la ciudad involucran la activación de los mapas cognitivos, porque "todo desplazamiento implica previamente un desplazamiento mental" (De Castro, 1997:40). El individuo para usar el espacio debe adaptarse y apropiarse de éste, trayendo como consecuencia que sus acciones intervienen en el medio natural transformándolo en un medio geográfico.

La imagen mental de la ciudad resalta "la existencia de estrechas relaciones entre los individuos y el medio, se reflejan en la percepción colectiva del entorno y en el comportamiento de los ciudadanos" (Zárate, 1991: 85), ya que la mayoría de las personas sienten una vinculación estrecha con su propio barrio, área residencial que mentalmente la reconocen y se identifican con ellos mismos, esto es potenciado por la fuerte relación entre el sentido del lugar y espacio actividad.

En otros términos, la vida cotidiana no sólo constituye el espacio de lo emocional en las relaciones interpersonales, sino que también "conforma un ámbito de creación y construcción de la sociedad, dentro del cual se expresan y aparecen tendencias de cambio" (Di Tella, 1989:614). Desde esta perspectiva la vida cotidiana "nos remite al estudio de la forma en que las personas producen y reproducen su existencia social. En este espacio de lo social, las personas se 
apropian del mundo objetivado, a través por ejemplo de formas lingüísticas para categorizar y conceptualizar cualquier comprensión de la realidad de la vida cotidiana." (Di Tella, 1989:614).

A partir de lo planteado en este recorrido, es posible determinar la manera como las formas y condiciones de reconocimiento, fijación y apropiación de los espacios, lugares y prácticas propias de los centros urbanos, están condicionados por procesos de categorización a partir de los cuales se logra identificar, definir y representar individual o colectivamente el tipo de relación de los sujetos con el medio en el cual se desarrolla su existencia diaria. De allí que de acuerdo con el tipo de experiencia que se activa en el contacto con otros grupos humanos en un mismo espacio, se establecen mapas cognitivos que permiten comprender e interpretar la construcción que se hace de un territorio, por parte de quienes lo habitan, lo transitan o recurren a él por razones muy concretas de orden comercial, cultural, educativo.

En síntesis, la configuración de los espacios cotidianos, tanto como la apropiación de los mismos por parte de los diferentes grupos humanos a partir de prácticas y actividades de resignificación, permite plantear la articulación de las ciudades, y en concreto de los centros urbanos, con la adecuación de las formas de vida y los esquemas mentales que determinan y condicionan las conductas individuales y colectivas de sus habitantes. De igual manera, el lugar que ocupa el lenguaje como herramienta de categorización y conceptualización de los modos de nombrar, simbolizar y representar, es una muestra de los mecanismos que permiten la interpretación y comprensión de las relaciones sociales vinculadas con la dimensión espacial.

Recibido: $12 / 12 / 2016$

Aceptado: 8/10/2017

\section{Bibliografía}

AUGÉ, M. (1993). Los no-lugares. Espacios del anonimato. Barcelona: Gedisa. AUGÉ, M. (1996). El sentido de los otros. Actualidad de la Antropología. Barcelona: Paidós. Barcelona.

BACHELARD, G. (1975). La poética del espacio. México: F.C.E.

BAILLY, A.S. (1979). La percepción del espacio urbano. Ed. I.E.A.L. Madrid.

BOURDIEU, P. (1988). Espacio social y poder simbólico. En: Cosas Dichas. Buenos Aires: Gedisa. pp. 127-143.

BOURDIEU, P. (1990). Algunas propiedades de los campos. En: Sociología y Cultura. México: Grijalbo. Pp. 135-141

BOURDIEU, P. (1995). Habitus, illusio y racionalidad. En: Bourdieu, Pierre y Wacquant, Loïc. Respuestas por una antropología reflexiva. México: Editorial Grijalbo.

BUZAN, T. (2004) Mapas Mentales [en línea]. México. Buzan Centres. 2004. Recuperado de: http://www.oficinaonline.com/buzanmx/tonybuzan/ (Consulta: 17 junio, 2004). 
CAPEL, H (1975). Definición de lo urbano [en línea]. Barcelona. Universidad de Barcelona. Scripta Vereta, Edición electrónica de trabajos publicados sobre geografía y ciencias sociales. Estudios Geográficos, no. 138-139 (1975). Recuperado de: http://www.ub.es/geocrit/sv-33.htm (Consulta: 14 octubre, 2004).

DE CASTRO, C. (1997). La geografía en la vida cotidiana. Barcelona: Ediciones del Serbal.

DE CASTRO, C. (1999) Mapas cognitivos, qué son y cómo explorarlos [en línea]. Barcelona. Universidad de Barcelona. Scripta Nova, Revista Electrónica de Geografía y Ciencias Sociales, no. 33. Recuperado de: http://www.ub.es/geocrit/sn-33.htm (Consulta: 4 noviembre, 2004).

DURÁN, M.A. (1998). La ciudad compartida: conocimiento, afecto y uso. Ed. Consejo Superior de los Colegios de Arquitectos de España, Madrid.

LINDÓN, A. (2000). La espacialidad como fuente de las innovaciones de la vida cotidiana. Hacia modos de vida cuasi fijos. En: La vida cotidiana y su espaciotemporalidad. Barcelona: Anthropos.

LÓPEZ, A. y MARTíNEZ, E. (2002) El desarrollo de la morfología social y la interpretación de las grandes ciudades [en línea]. Barcelona. Universidad de Barcelona. Scripta Nova, Revista Electrónica de Geografía y Ciencias Sociales. Vol.6, no. 112 (15 de abril 2002). Recuperado de: http://www.ub.es/geocrit/sn/sn-112.htm

SANTOS, M. (1996). Metamorfosis del espacio habitado. Barcelona: Oikos Tau. STERNBERG, R. (1987). Inteligencia humana II: Cognición, personalidad e inteligencia. Barcelona: Paidós.

WOLF, M. (1988). Sociologías de la vida cotidiana. Madrid: Cátedra. 